\title{
Speed management on local government managed roads - research, recommendations and guidelines
}

\author{
Marcin Budzyński ${ }^{1,}{ }^{*}$, Stanisław Gaca $^{2}$, and Mariusz Kieć ${ }^{2}$ \\ ${ }^{1}$ Gdansk University of Technology, Faculty of Civil and Environmental Engineering, Gdansk, Poland \\ ${ }^{2}$ Cracow University of Technology, Faculty of Civil Engineering, Cracow, Poland
}

\begin{abstract}
Commissioned by the National Road Safety Council Secretariat, the project "Guidelines for speed management on local government managed roads" studied car driver behaviour when subjected to selected speed management measures such as: local speed restrictions, surveillance, traffic calming and restricted speed areas. In addition, analyses were conducted on the impact of selected measures on the level of road safety. The behaviour was assessed by studying the changes in speed parameters (statistical characteristics) for the particular speed management measures or their absence. The road safety level was measured by comparing the level before and after the implementation of the particular speed management measure, taking trends into account. The paper presents the results of the research, along with recommendations for speed management guidelines.
\end{abstract}

\section{Introduction}

Speed management is a set of measures designed to set reasonable speed limits and influence the drivers' choice of speed. This can be achieved through urban planning, infrastructure and traffic layout, enforcement, education and advanced technologies. The basic goal of speed management is to achieve a state of traffic where vehicle speeds are adjusted to the road and traffic making the speeds potentially safe. If properly managed, speed control can help reduce traffic noise and air pollution.

There is evidence from research and practical experience that road safety can be significantly improved through consistent speed management, which includes road engineering measures. There are a number of engineering solutions that can help to reduce vehicle speeds such as road infrastructure design that helps drivers to choose the right speed, physical means to control driving speed and reasonable speed limits. Some of the measures are not very restrictive and leave the decisions to drivers (how willing they are to accept a restriction) and local road and traffic conditions. In this case the actual benefits from changing speeds and better road safety depend on social and cultural factors. As a consequence, overreliance on the results of international speed management research may not offer the same effects in Central and Eastern European countries. This has prompted new research into how different speed management measures affect driver behaviour and road safety. The paper describes the effectiveness of selected speed management measures and

\footnotetext{
Corresponding author: $\underline{\text { mbudz@.pg.gda.pl }}$
} 
the effect they have on road safety. To that end the power model was used. It was calibrated based on research results.

\section{The effects of speed management on road safety}

The effectiveness of speed management measures and how they contribute to better road safety can be analysed using direct (road incident data - collisions and accidents) or surrogate measures that describe the potential hazards. One way to understand the effects of speed management on road safety is to estimate how a specific safety measure has changed. The rate is a quotient of the assumed change in safety on a treated section and the mean value of that same measure on an untreated control section. This is referred to in the Highway Safety Manual as CMF (Crash Modification Factor) which is the basic rate with which to evaluate how different road safety treatments change road safety [1].

The effects of a speed management measure on road safety can also be estimated using surrogate rates such as change in vehicle speed as a result of the measure. There is evidence that speed can be used as a surrogate road safety rate known from international and Polish research. The statistical relation between speed and road safety is logical and has been demonstrated many times before [2-7]. To estimate how a change in vehicle speed triggers a change in road safety, we can use the "power model" [4]. It helps to predict accidents and accident casualties based on the difference in mean speed "before" and "after" a measure has been applied. To this end, the equation below is used:

$$
W_{1}=\left(V_{1} / V_{0}\right)^{a} * W_{0}
$$

where:

- $W_{0}$ - selected road safety measure in the observation period prior to treatment,

- $W_{1}$ - selected road safety measure in the same observation period after the treatment,

- $V_{0}$ - average speed prior to treatment $[\mathrm{km} / \mathrm{h}]$,

- $V_{1}$ - average speed after the treatment $[\mathrm{km} / \mathrm{h}]$,

- $a$ - model parameter with the value based on literature or set individually.

A key assumption when using the relation (1) is that during the "before" and "after" analysis, none of the other road safety determinants change, except speed. Research described in [4] was used to determine the following values of $a$ in equation (1) (Table 1).

Table 1. Total time from the first look until the target is passed and Time during which driver's gaze is fixed on target (ms) in 4 analysed situations [4].

\begin{tabular}{|c|c|c|c|c|}
\hline \multirow{2}{*}{ Type of accident } & \multicolumn{2}{|c|}{ Rural roads } & \multicolumn{2}{c|}{ Urban roads } \\
\cline { 2 - 5 } & a parameter & $\begin{array}{c}\text { Confidence } \\
\text { level } 95 \%\end{array}$ & a parameter & $\begin{array}{c}\text { Confidence } \\
\text { level } 95 \%\end{array}$ \\
\hline Fatality accident & 4.1 & $2.9 \div 5.3$ & 2.6 & $0.3 \div 4.9$ \\
\hline Fatality and serious injury accident & 2.6 & $-2.7 \div 7.9$ & 1.5 & $0.9 \div 2.1$ \\
\hline Total accidents involving casualties & 1.6 & $0.9 \div 2.3$ & 1.2 & $0.7 \div 1.7$ \\
\hline
\end{tabular}

If we assume the above $a$ values, in the case of urban roads, a speed limit reduction from $60 \mathrm{~km} / \mathrm{h}$ to $50 \mathrm{~km} / \mathrm{h}$, for the average baseline speed of $60 \mathrm{~km} / \mathrm{h}$ and a speed reduction of 2.5 $\mathrm{km} / \mathrm{h}$, fatality accidents would drop by $10.5 \%$ with total accidents going down by $5 \%$. With improved speed limit compliance (e.g. through enforcement or physical means of traffic calming) and a real reduction in average speed by $5 \mathrm{~km} / \mathrm{h}$, fatality accidents could drop by $21 \%$ and total accidents by $10 \%$.

Figure 1 shows an example of how the VTI power model can be used to estimate the effects of changing the mean speed on a specific road section on the percentage of accidents of different degrees of severity. The figure shows how a change in mean speed on a road 
section (by $3 \mathrm{~km} / \mathrm{h}, 6 \mathrm{~km} / \mathrm{h}, 9 \mathrm{~km} / \mathrm{h}, 12 \mathrm{~km} / \mathrm{h}$ or $15 \mathrm{~km} / \mathrm{h}$ ) can potentially improve road safety relative to the mean speed before the change.

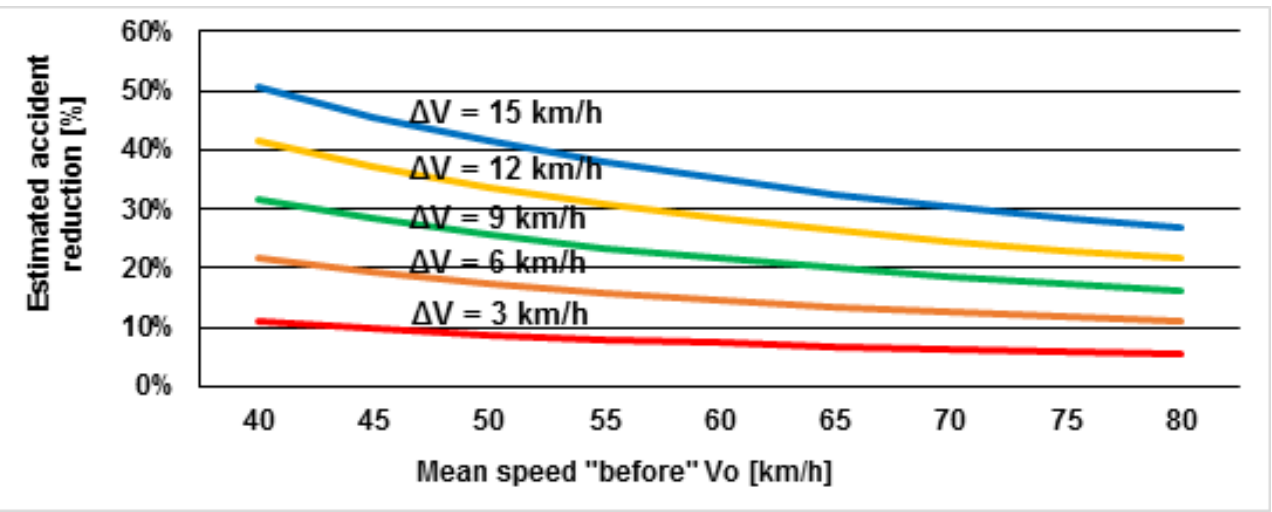

Fig. 1. Estimated reduction in fatal and serious injury accidents in relation to the initial mean speed and speed reduction $\Delta \mathrm{V}$ - roads in built-up areas [8]

As well as the less restrictive measures, physical traffic calming measures are also used. These are much more effective and include speed bumps and raised surfaces. International research [9] suggests that speed bumps are highly effective and help to reduce vehicle speeds by about $32 \mathrm{~km} / \mathrm{h}$ and about $27 \mathrm{~km} / \mathrm{h}$ when speed tables are applied. Raised pedestrian crossings used as an obstacle produce results similar to speed bumps with average speed reductions by $4.0 \div 6.5 \mathrm{~km} / \mathrm{h}$. Please note, however, that while speed bumps reduce speed locally, speed increases in between the bumps which increases emissions (accelerating and braking is more frequent). This is why it makes more sense to use comprehensive traffic calming measures with speed reductions distributed evenly on a designated road section. Mini roundabouts and small roundabouts in place of regular junctions reduce average speed by $36 \mathrm{~km} / \mathrm{h}$ and $54 \mathrm{~km} / \mathrm{h}$ respectively.

The results make it very clear that speed management is most effective when physical traffic calming measures are used. Despite that, before any such treatment, an analysis should be conducted to look at the effectiveness of other measures such as active speed limit signs, intensive enforcement, adding or removing lines separating traffic lanes and allowing vehicles to be parked along the road.

\section{Research and results}

Research into the effectiveness of speed management measures included accident and casualty analyses "before" and "after" a treatment (in locations where the date of a treatment was known). If the date of a treatment was not known, the trends in accident numbers were analysed. Surrogate safety measures were studied too, i.e. vehicle speeds. The research covered the following cases:

- local speed limits (Figure 2a and b) - 44 locations for accident analysis and 27 locations for speed analysis

- TEMPO 20 residential area (Figure 2c) - 10 locations for accident analysis and 8 locations for speed analysis

- TEMPO 30 area speed limit (Figure 2d) - 35 locations for accident analysis and 12 locations for speed analysis

- sections with mild traffic calming measures (change in vehicle trajectory while providing good passage for heavy vehicles, Figure 2e) - 33 locations for accident analysis and 29 locations for speed analysis 
- sections with additional signs to inform of a possible speed control on the section (Figure 2f) - 30 locations for accident analysis and 12 locations for speed analysis.

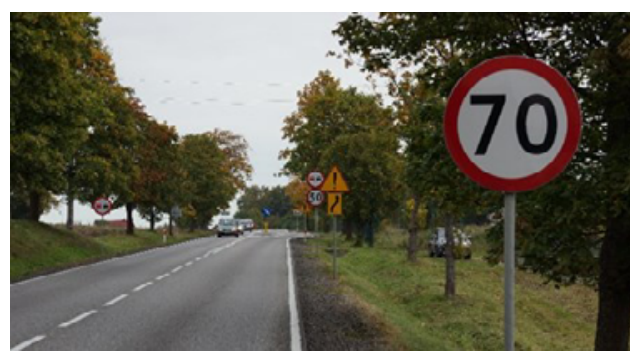

a)

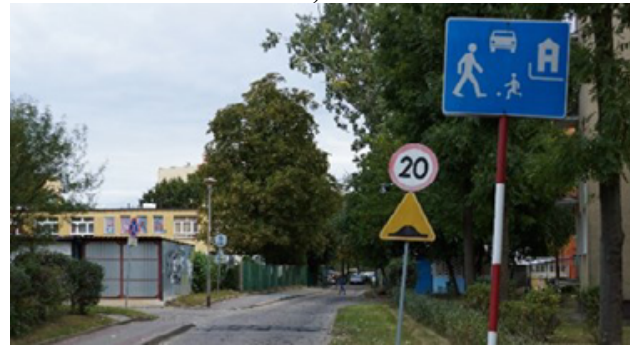

c)

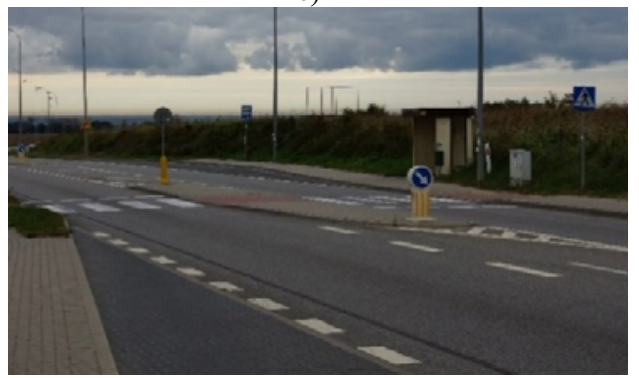

e)

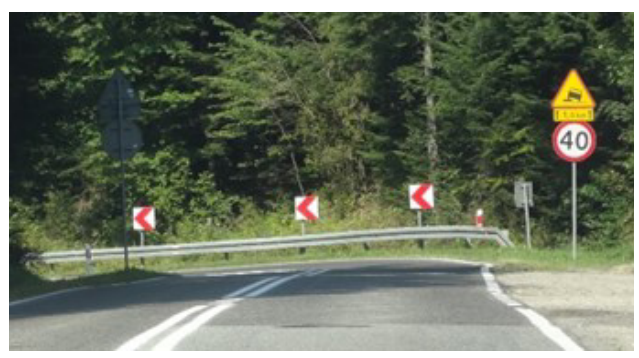

b)

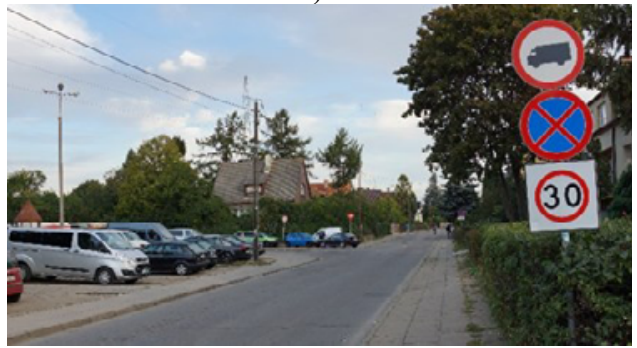

d)

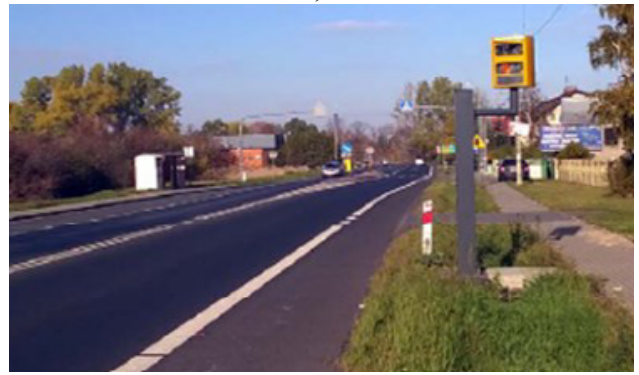

f)

Fig. 2. Examples of analysed speed management measures [8].

\subsection{Speed analysis}

Due to the conditions on site, speed was measured using three measurement methods:

- manual (observations in the field in subsequent measurement cross-sections or analysis of recorded video footage),

- automatic (pneumatic detectors)

- a combination of manual and automatic measurements.

Manual measurements helped to determine vehicle speeds in free flow traffic only, split into two types of vehicles (light and heavy vehicles). The advantage of the method is that it is done without the drivers noticing. This method was used in Tempo 20 and Tempo 30 zones and in the case of local speed limits.

Automatic measurements helped to ensure that speed was recorded very accurately while differentiating between vehicle speeds in the entire traffic flow and in free flow traffic. The test devices were able to identify vehicle types. This method was used on sections with local speed limits, mild traffic calming measures and on speed control sections. 
Speed was measured on sections with speed management measures and on control sections (with no speed management measures). In the case of area speed limits the control sections were selected on streets with Tempo 20 and Tempo 30 characteristics. Mild traffic calming measures were represented by results from sections of a similar characteristic (roadside, cross-section, accessibility). Untreated sections of the same road were also considered. Local speed limits and section control were represented by the following crosssections: app. $150 \mathrm{~m}$ before the sign (as a control section), at the sign and behind it (app. 150 $\mathrm{m})$. Control sections representing local speed limits had similar geometrical parameters. The results show that:

- local speed limits help to reduce average speed significantly compared to the control crosssection (no speed restrictions). The reduction depends on the limit and changes from app. $6.8 \%$ to $14.5 \%$ on treated sections;

- temporary speed enforcement signs help to reduce speed for longer compared to speed cameras. This measure reduces average speed by about $15.8 \%$ compared to the control section;

- mild traffic calming measures help to reduce average speed by about $10.3 \%$ with vehicle speeds becoming similar;

- while Tempo 30 zones help to reduce speed by app. 16.3\% compared to control sections, the spread of speeds was quite strong with speeds depending on the local road conditions and environment;

- residential area (Tempo 20) results show a speed reduction by about $13.4 \%$ in free flow traffic compared to control sections. Just as with Tempo 30 zones, the spread of speeds was significant and depended on local road conditions. Please note the high percentage of drivers going above the speed limit in residential areas.

Fig. 3 shows examples of test results when the speed limit was changed to $70 \mathrm{~km} / \mathrm{h}$ in a non-built-up area and a comprehensive traffic calming treatment was introduced in a small town (for free-flow). Results of the analysis show that a local speed limit of $70 \mathrm{~km} / \mathrm{h}$ on average:

- reduces mean speed by $9.3 \mathrm{~km} / \mathrm{h}$ for free-flowing vehicles; compared to the control crosssection the reduction is by $11 \%$;

- reduces V85 by $10 \%$ for free-flow traffic,

- the averaged standard deviation changes compared to the control cross-section which suggests that the local speed limit has not improved traffic homogeneity.

Analysis of a group of road sections with calmed traffic in small towns shows that this treatment:

- reduces average speed by $2.8 \mathrm{~km} / \mathrm{h}$ for free-flow; this is a $5 \%$ reduction compared to the control cross-section;

- reduces V85 speed by 7\% for free-flow but the effect differs from site to site and ranges from an increase of $2 \%$ to a decrease of $27 \%$; this strong variation may be the result of the traffic calming measures used;

- reduces standard deviation by $1.7 \mathrm{~km} / \mathrm{h}(16 \%)$ for free-flow compared to the control crosssection which shows that comprehensive traffic calming treatment on roads passing through small towns improves traffic homogeneity. 

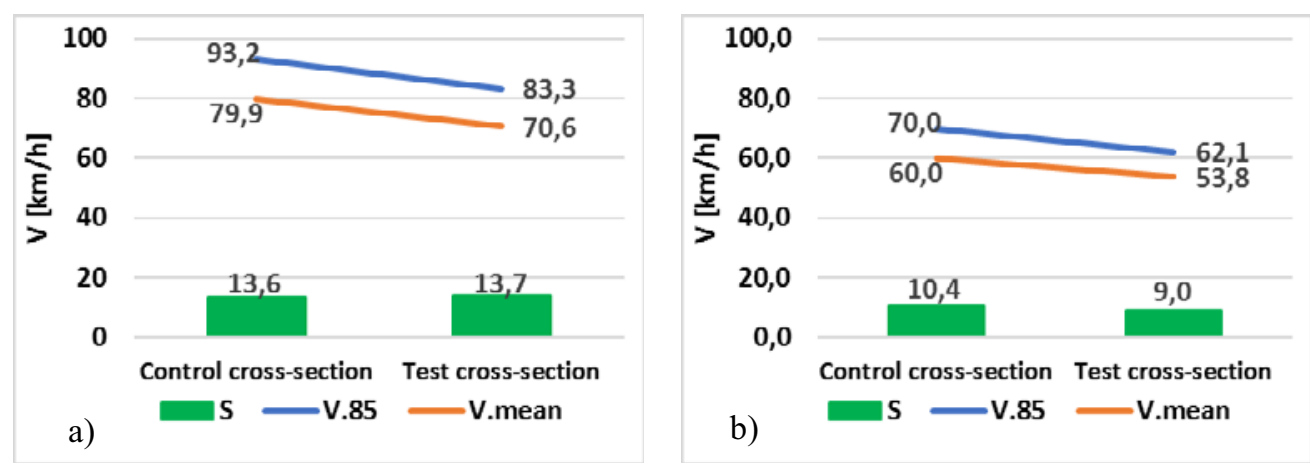

Fig. 3. Average speed reduction in free -flow ( - Local speed limit $-70 \mathrm{~km} / \mathrm{h}, \mathrm{b}$ - Comprehensive traffic calming in a small town [8].

\subsection{Accident analysis}

With limited data availability, the analysis of speed management effectiveness was simplified. The annual number of accidents and casualties was determined for all the locations under analysis from 2006 to 2014. The next step was to choose those locations whose date of treatment was known and fell within the period $2007-2013$. Once selected, the locations were then analysed for their annual average road safety rates "before" and "after" the treatment. This produced the quotients of the "after"/"before" measures under estimation for the specific speed management measures. The lower the value of the quotient, the higher the effectiveness of the measure. This is a typical approach to "before" and "after" effectiveness evaluations. Because accidents may change regardless of the treatment, an additional comparison was made of the quotients to general accident trends in the regions under analysis. The effectiveness of the measures was estimated by comparing the "after" quotients to the "before" situations for the treated sites and control sections. The bigger the difference between treated site and control section values, the more effective the treatment is (under the assumption that test site values are lower than those in control areas).

Table 2 lists the effectiveness indicators of the speed management measures and the resulting accident and casualty reduction. Because residential areas have a low number of accidents (Tempo 20), those test sites were analysed together with Tempo 30 zones.

Table 2. Analysis of the effects of speed management on road safety [8].

\begin{tabular}{|c|c|c|}
\hline Measure & Accident reduction & $\begin{array}{c}\text { Fatality and serious injury } \\
\text { reduction }\end{array}$ \\
\hline Local speed restriction & $22 \%(26 \%$ - speed-related $)$ & $15 \%(18 \%$ - speed-related $)$ \\
\hline Intensive enforcement & $45 \%(52 \%$ - speed-related $)$ & $48 \%(56 \%$ - speed-related $)$ \\
\hline $\begin{array}{l}\text { Traffic calming on roads in } \\
\text { small towns }\end{array}$ & $\begin{array}{c}\text { No statistically significant } \\
\text { impact }\end{array}$ & $\begin{array}{c}\text { No statistically significant } \\
\text { impact }\end{array}$ \\
\hline $\begin{array}{c}\text { Traffic calming on roads in } \\
\text { cities }\end{array}$ & $17 \%(25 \%$ - speed-related $)$ & $14 \%$ \\
\hline Tempo 20, Tempo 30 & $\begin{array}{c}\text { No statistically significant } \\
\text { impact }\end{array}$ & $12 \%(30 \%$ - speed-related $)$ \\
\hline
\end{tabular}


The results show that speed enforcement (speed control section signs) and area speed limits are effective in improving road safety. It is important to note, however, that the results are based on a relatively small sample and more research is required.

With the evaluation of how different speed management measures affect road safety on Poland's lower class roads, it is clear that the effects differ from measure to measure. Using the results of "before" and "after" comparisons and taking account of the general road safety trends, the following are the initial evaluations of how the particular measures affect road safety:

- no positive effects were established in Tempo 20 and Tempo 30 zones on accident reduction. Fatalities and serious injuries, however, are down - the average reduction rate being 30\% (accidents involving speed);

- contrary to expectations, mild traffic calming measures had no positive effect on accident reduction or casualty reduction;

- sections of roads with local speed limits have seen a positive effect of the restrictions with fewer accidents (a $22 \%$ reduction) and serious injuries and deaths (a 15\% reduction);

- sections with speed limit enforcement measures have seen very positive effects both in terms of accidents (a 45\% reduction) and serious injuries and deaths (a 48\% reduction).

\subsection{Power model calibration}

The next step of the analysis was to calibrate the "a" parameter for the "power model" given in equation (1) using the speed results and accident analysis. The factors calculated include speed-related accidents, severity of all accidents and speed-related accidents which should have a strong relation to speed. Table 3 gives the parameter's values for the measures analysed. The "a" parameter for local speed limits has not been evaluated because of insufficient accident sample for each value of a speed limit.

Table 3. The "a" parameter in the "power model" equation based on authors' research

\begin{tabular}{|c|c|c|c|}
\hline \multirow{2}{*}{ Speed management measure } & \multicolumn{3}{|c|}{ Power model's $\boldsymbol{a}$ parameter } \\
\cline { 2 - 4 } & $\begin{array}{c}\text { Speed-related } \\
\text { accidents }\end{array}$ & $\begin{array}{c}\text { Total serious } \\
\text { injuries and } \\
\text { fatalities }\end{array}$ & $\begin{array}{c}\text { Speed-related } \\
\text { serious injuries and } \\
\text { fatalities }\end{array}$ \\
\hline Speed limit & - & - & - \\
\hline Residential area (TEMPO 20) & 3.2 & 3.0 & 5.2 \\
\hline TEMPO 30 & 2.6 & 2.4 & 4.2 \\
\hline Mild traffic calming measures & 2.6 & 0.0 & -1.0 \\
\hline Speed control sections & 6.0 & 4.9 & 6.3 \\
\hline
\end{tabular}

\section{Conclusion}

The research into the effects of speed management measures on road safety shows that the measures have a varying effect on safety when measured with direct rates such as accidents and accident severity and with indirect rates such as vehicle speed.

The studies confirmed a highly beneficial effect of speed intensive surveillance as a measure to improve road safety. Local speed restrictions (B-33 signs) do not generally bring the desired speed, but significantly affect speed reduction and decrease the number of 
accidents and casualties. Recorded speed reduction in the local restriction areas by $9.3 \div 11.9$ $\mathrm{km} / \mathrm{h}(11.6 \% \div 14.6 \%)$ means a potential decrease in the number of accidents with fatalities and serious injuries by approx. $27 \div 34 \%$ - on roads outside built-up areas. Traffic calming on through road sections caused a slight reduction in speed but did not have a statistically significant effect on road safety improvement - this may result from the specifics of the applied traffic calming measures

Traffic calming on street sections in towns did not result in average speed reduction. There was no statistically significant impact on accident reduction, but a decrease in the number of fatalities and serious injuries was observed - this surprising result of the research may be associated with the specifics of the applied traffic calming measures. In the $30 \mathrm{~km} / \mathrm{h}$ and $20 \mathrm{~km} / \mathrm{h}$ zones a decrease was registered in fatality and serious injury accidents. While "mild" calming measures are not very effective, physical measures such as speed bumps and raised junctions proved to be very effective.

The results can be used to build "power models" that help to understand the effectiveness of speed management measures. This will ensure that proposed treatments will offer the best effectiveness for a given set of conditions.

\section{References}

1. Highway Safety Manual (HSM) (AASHTO, Washington DC, 2010)

2. M.H. Cameron, R. Elvik, Nilsson's Power Model connecting speed and road trauma: Applicability by road type and alternative models for urban roads, Accid. Anal. Prev. 42 pp. 1908-1915 (2010)

3. S. Gaca, Study of vehicle speed and its impact on road safety (Cracow University of Technology, 2002)

4. R. Elvik, A. Hoye, T. Vaa, M. Sorensen, The handbook of road safety measures. The second edition (Emerald Group Publishing, 2009)

5. Austroads Ltd., Infrastructure/speed limit relationship in relation to road safety outcomes, AP-T141/10 (2010)

6. S. Gaca, M. Kieć, Vehicle responsiveness tests to change speed limits on built-up areas, Urban Reg. Transp. 12 (2005)

7. K. Jamroz, W. Kustra, M. Budzyński, J. Żukowska, Pedestrian protection, speed enforcement and road network structure as the key action for implementing Poland's Vision Zero, Transp. Res. Procedia. 14 pp. 3905-3914 (2016). doi:10.1016/j.trpro.2016.05.479

8. S. Gaca, M. Budzyński, M. Kieć, Guidelines for speed management on local government managed roads (Secretariat of the National Road Safety Council, 2016)

9. Federal Highway Administration, Speed management: A manual for local rural roads owners, FHWA-SA-12-027 (U.S. Department of Transportation, 2012) 